\title{
UUR UUREY
}

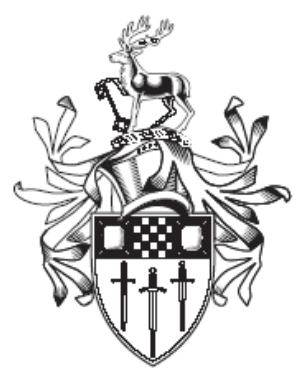

\section{Discussion Papers in Economics}

\section{OPENNESS, EFFICIENCY AND TECHNOLOGY: AN INDUSTRY ASSESSMENT}

\author{
By \\ Dimitris Christopoulos \\ (Panteion University) \\ \& \\ Peter McAdam \\ (University of Surrey and European Central Bank) \\ DP $08 / 12$ \\ Department of Economics \\ University of Surrey \\ Guildford \\ Surrey GU2 7XH, UK \\ Telephone $+44(0) 1483689380$ \\ Facsimile +44 (0)1483 689548 \\ Web www.econ.surrey.ac.uk \\ ISSN : $1749-5075$
}




\title{
OPENNESS, EFFICIENCY AND TECHNOLOGY: AN INDUSTRY ASSESSMENT
}

\author{
Dimitris Christopoulos* and Peter McAdam ${ }^{\dagger}$
}

June 13, 2012

\begin{abstract}
Most growth models imply positive impacts on economic growth from greater openness. And a key factor linking openness and growth is the efficiency with which resources are used. Empirically, however, the efficiency impacts of trade have been ambiguous. Using a stochastic frontier analysis, we examine the impact of openness on technical (in)efficiency for a sample of OECD economies. Unlike the bulk of related studies, we work at the industry level. Given recent debates on technology-inspired growth and TFP effects, we additionally examine whether ICT expenditures impacts openness and efficiency. We establish the elasticity of openness with respect to (in)efficiency; TFP and Scale Economies; and Technical Inefficiency across countries and sectors. Both openness and ICT usage have robustly positive impacts on efficiency. Our results shed light on the impact of, spillovers between, and heterogeneity across countries and industries from, increasing openness interacted with the use of advanced technologies.
\end{abstract}

*Panteion University.

${ }^{\dagger}$ European Central Bank and University of Surrey. 


\section{Introduction}

In the context of a stochastic frontier analysis, we examine the impact of openness on technical (in)efficiency for a sample of OECD economies. We make two innovations. First, unlike the bulk of related studies, we examine results at the industry level. This facilitates a detailed perspective, less prone to aggregation biases. Indeed, as far as we know, this is the first study of its type relating openness and inefficiency among the OECD manufacturing sector. ${ }^{1}$ Second, given debates in recent years of technology-inspired growth and TFP effects, we additionally examine how an increasing share of Information and Communication Technologies (ICT) matters for and bolsters the positive impact of openness on efficiency.

As is well known, most growth models imply positive impacts on economic growth from greater openness. And a key factor linking openness and growth is the efficiency with which resources are used. Typically the literature highlights the following mechanisms by which openness enhances efficiency (e.g., Miller and Upadhyay (2000)): through greater economies of scale; intensifying competition and hence encouraging managerial efficiency; through technology diffusion; by encouraging market liberalization and integration. Notwithstanding the appeal of such arguments, the efficiency impacts of trade have been contentious and difficult to pin down in the literature (e.g., Edwards (1998)).

An additional issue is whether openness and efficiency interact with the use of ICT capital; many have attributed growth and TFP differences over recent decades between economies to their use of certain information technologies - see, for instance, Oliner and Sichel (2000), van Ark and Inklaar (2005), Mas (2006), McQuinn (2009); and Solow (1987) and Brynjolfsson (1993), for a more sceptical viewpoint. Uncertainty on the impact of these channels is unfortunate since the interaction between openness, ICT capital usage and efficiency are areas of intense policy relevance and debate (e.g., policies relating to patent restriction, industrial policy, tax policy).

Uncovering both of these mechanisms - openness and efficiency, and ICT usage and TFP - is the purpose of this study. The paper is organized as follows. Section II discusses the model. Within a Stochastic Frontier setting,

\footnotetext{
${ }^{1}$ The choice of the manufacturing sector is natural since - compared to Services and Government sectors - its degree of openness in final and intermediate products is high.
} 
we use a Translog cost function frontier where total cost is assumed to deviate from the optimal cost by a random disturbance, $v$, and an inefficiency term, $u$. Openness and relative ICT capital enters as covariates into the inefficiency equation. The translog cost function and the inefficiency equation are estimated in one stage. The translog form is a particularly flexible and encompassing form. It nests Cobb Douglas which then provides a testable special case. Section III examines the country and sectoral data used in our study; we merge the production and cost data from the EU-KLEMs data set with openness measures derived by the OECD. Section IV provides the maximum likelihood estimation results of the cost functions as well as a number of parameter constraints relating to functional form and the specific impacts of openness and ICT usage. This is then followed by additional evidence on openness elasticities, TFP decompositions and technical inefficiency metrics. It turns out - despite the heterogeneity of the data set - that a number of clustering and uniformities can be uncovered in the data, as well as, the result that openness has a robust positive impact on efficiency at the industry level. Finally, we conclude.

\section{The Model}

We consider a Translog cost frontier. ${ }^{2}$ According to duality theory, any continuous function of factor input prices that is non decreasing, homogeneous and concave, is a cost function that summarizes production. Its use in fact precludes the need to specify a particular production function and serves as a local, second-order approximation to an arbitrary cost function.

A cost function is preferred to a production function on the basis that prices and output are exogenous while input quantities are imperfectly exogenous variables. In addition the selection of optimal mix for some sets of exogenous prices normally assumes cost minimization and no output maximization, e.g., Fuss, McFadden, and Mudlak (1978).

Within this framework total cost is assumed to deviate from the optimal cost by a random disturbance, $v$, and an inefficiency term, $u$. Let the cost

\footnotetext{
${ }^{2}$ The Translog general form is a highly flexible functional form. Its derivation as taylorseries expansion of a Cobb Douglas function goes back essentially to Kmenta (1967). See also the discussion in León-Ledesma, McAdam, and Willman (2010).
} 
function be, ${ }^{3}$

$$
\begin{aligned}
c_{i j t} & =\alpha+\alpha_{i}+\alpha_{j} \\
& +\gamma_{k} \cdot p_{k, i j t}+\gamma_{l} \cdot p_{l, i j t}+\frac{\gamma_{k k}}{2} \cdot p_{k, i j t}^{2}+\frac{\gamma_{l l}}{2} \cdot p_{l, i j t}^{2} \\
& +\gamma_{k l} \cdot p_{k, i j t} \cdot p_{l, i j t}+\gamma_{T} T+\frac{\gamma_{T T}}{2} T^{2}+\gamma_{k T} \cdot p_{k, i j t} \cdot T+\gamma_{l T} \cdot p_{l, i j t} \cdot T \\
& +\gamma_{k y} \cdot p_{k, i j t} \cdot y_{i j t}+\gamma_{l y} \cdot p_{l, i j t} \cdot y_{i j t}+\gamma_{y} \cdot y_{i j t}+\frac{\gamma_{y y}}{2} y_{i j t}^{2} \\
& +v_{i j t}+u_{i j t}
\end{aligned}
$$

where subscripts $i=1, \ldots, N, j=1, \ldots, M$ and $T=1,2, \ldots$ denote country, industry and year respectively; $Y$ denotes output; and $x=\log (X)$ etc. Variable $T$ is a linear time trend that proxies exogenous technical progress. In our case, this is non-neutral technical progress since it accrues to both capital and labor components. $\alpha_{i}$ and $\alpha_{j}$ show country and industry-specific effects respectively and are introduced to distinguish unobserved heterogeneity from the inefficiency component as in Greene (2005).

The price of labor $P_{L}$, is defined as,

$$
P_{L}=\frac{\text { Wages }+ \text { Salaries }}{N}
$$

where $N$ is employment, and wages and salaries are deflated by value added sectoral deflators. The price of Capital, $P_{K}$, is given by,

$$
P_{K}=\frac{V A-(\text { Wages }+ \text { Salaries })}{K}
$$

where $K$ is the fixed stock of capital formation, and $V A$ denotes value added.

Value added is expressed at constant prices using VA-sectoral deflators. Total cost is therefore,

$$
C=P_{K} K+P_{L} L
$$

Finally in equation (1), the term $u_{i j t}$ is a one-sided error component representing "technical inefficiency" and is assumed to be distributed independently and obtained by truncation at zero of $u_{i j t} \sim N\left(z_{i j t} \beta^{\prime}, \sigma_{u}^{2}\right) . z_{i j t}$ is a

\footnotetext{
${ }^{3}$ Following Griffin and Gregory (1976), Fuss (1977), Christopoulos (2000) and Farsi, Filippini, and Greene (2005), we use a value added approach in calculating the price of capital.
} 
vector of variables that influence technical inefficiency and $\beta$ is a vector of the associated parameters.

Technical inefficiency in the cost frontier $u_{i j t}$, is modeled as follows,

$$
u_{i j t}=\beta+\beta_{T} T+\left(\beta_{o}+\beta_{o T} T+\beta_{\text {oict }}\left(\frac{K^{i c t}}{K^{n i c t}}\right)_{i j t}\right) O P E N_{i j t}+w_{i j t}
$$

where $O P E N$ represents the degree of openness as measured by the ratio of (imports + exports) to output. The term, $\frac{K^{i c t}}{K^{\text {nict }}}$, refers to the ratio of ICT capital services to non-ICT capital services.

The specification of inefficiency in relation to openness shows that the effect of openness on inefficiency can be disaggregated into a shift effect, $\beta_{o}$, as well as a slope effect, $\beta_{o T} T+\beta_{\text {oict }}\left(\frac{K^{i c t}}{K^{\text {nict }}}\right)$. The former effect simply states that, other things being equal, a greater degree of trade openness imparts a positive effect on efficiency. However, since trade openness evolves slowly, we would expect this impact to similarly evolve modestly. The latter channel the slope effect - conversely suggests that the effect of increasing openness is amplified over time and specifically interacts with ICT expenditures.

The final term in $(5), w_{i j t}$, is assumed to be independently distributed, obtained by truncation of the normal distribution with mean zero and unknown variance $\sigma_{w}^{2}$, such that $w_{i j t}$ is nonnegative $\left(w_{i j t} \geq-z_{i j t} \beta^{\prime}\right)$. These assumptions are consistent with the $u_{i j t}$ 's being a nonnegative truncation of the $N\left(z_{i j t} \beta^{\prime}, \sigma_{u}^{2}\right)$ distribution; see Battese and Broca (1997).

One advantage of such a set up is that is less restrictive with respect to other frontier models (see for example the models suggested by Reifschneider and Stevenson (1991)) which assume the $w_{i j t}$ random variables are nonnegative random variables having a half normal, exponential or gamma distribution. In the present model the $w_{i j t}$ random variables can be negative if $z_{i j t} \beta^{\prime}>0$ i.e., $w_{i j t} \geq-z_{i j t} \beta^{\prime}$, see Battese and Coelli (1995).

\section{Data}

We use data from the following Manufacturing sectors:

1. Food Products, Beverages \& Tobacco;

2. Textiles, Textile Products, Leather \& Footwear; 
3. Wood \& Products of Wood \& Cork;

4. Pulp, Paper, Paper Products, Printing \& Publishing;

5. Chemical, Rubber, Plastics \& Fuel Products;

6. Other Non-Metallic Mineral Products;

7. Basic Metals \& Fabricated Metal Products;

8. Machinery \& Equipment;

9. Transport Equipment;

10. Manufacturing Nec. \& Recycling.

The countries sampled are: Austria (1977-2006); Canada (1971-2003); Spain (1981-2004); Finland (1976-2006); Italy (1971-2006); Netherlands (19882006); USA (1978-2005); Germany (1992-2006); Denmark (1994-2005); Sweden (1994-2005). All series are taken from the KLEMs data base, with the exception of the $O P E N$ series, which is taken from the equivalent sectoral series in the OECD's STAN database. ${ }^{4}$ Sample sizes reflect the overlap of data sets. Moreover, these particular sectors (1-10 above) were chosen given their generally longer-dated (and more reliable) trade data relative to other sectors.

\section{Estimation Results}

Estimation of the set of equations (1) and (5) can be accomplished by Maximum Likelihood estimation. The likelihood function alongside its partial derivatives with respect to the parameters of the model are given in Battese and Coelli (1993).

Table 1 shows the estimates over four model specifications (denoted $\mathbb{M}_{1}$ to $\mathbb{M}_{4}$ ). We estimate both Translog and Cobb-Douglas cost function forms. The latter being a special case of the former and, notwithstanding its typical

\footnotetext{
${ }^{4}$ The underlying data for the OECD STAN and KLEMS databases may be respectively found at: http://stats.oecd.org/WBOS/index.aspx and http://www.euklems.net/index.html
} 
empirical performance, a common starting point for growth and businesscycle models and analysis. ${ }^{5} \mathbb{M}_{1}$ and $\mathbb{M}_{4}$ include industry and country dummies while $\mathbb{M}_{2}$ and $\mathbb{M}_{3}$ include country-specific intercepts only.

\section{[Insert Table 1 here]}

Overall, we also see that almost all parameters are significant at $1 \%$ and there is robust evidence that openness has a marked impact on reducing inefficiency across countries and sectors. Since models 2 and 3 are nested in 1 and 4, respectively, we conduct likelihood ratio tests on the joint significance of the industry dummies. Doing so for the translog case generates the test statistic of $\chi_{9}^{2}=719.08$ and $\chi_{9}^{2}=1247.38$ for Cobb Douglas (the latter unreported in Table 1). Both tests thus reject the null hypothesis of no heterogeneity across industries at the $1 \%$ level.

We also test a number of more generic parameter restrictions. These are listed at the bottom of Table 1. The first test is a test of the assumption of Cobb Douglas against Translog $\left(\mathbb{M}_{1}\right.$ against $\left.\mathbb{M}_{4}\right)$. At the $1 \%$ level of significance, the former specification is rejected in favor of the latter $\left(\chi_{9}^{2}=\right.$ 816.72). Thus the Translog cost function described by $\mathbb{M}_{1}$ is a superior functional choice across countries and industries. ${ }^{6}$

Note further that, although the positive effects of openness on efficiency are robust to whatever functional form is used, the statistically dominated Cobb Douglas appears to grossly underestimate its quantitative size (by an order of magnitude: -0.456 vs. $-0.027 ;-2.45$ vs. -0.958). This confirms and underscores the biases inherent in the mechanical use of Cobb Douglas commonly voiced at the aggregate level (e.g., Chirinko (2008), Klump, McAdam, and Willman $(2007 \mathrm{a}, \mathrm{b}))$ but now apparent at the industry level.

The second restriction, tests whether openness plays a role in the inefficiency equation; the non-rejection of this joint hypothesis otherwise reduces the inefficiency equation to the conventional specification. Since this

\footnotetext{
${ }^{5}$ Despite its popularity, Cobb Douglas is routinely rejected by aggregate and disaggregate data. For example, at the aggregate level Klump, McAdam, and Willman (2007a) and Chirinko (2008) suggest $0.4-0.6$ as a benchmark aggregate elasticity range for the US. Likewise, factor income shares (again at aggregate and disaggregate level) typically exhibit such protracted swings as to render Cobb Douglas grossly counter factual (see Jones (2003), McAdam and Willman (2013)).

${ }^{6}$ Further, the ratio of technical efficiency error to the purely stochastic error falls to barely above unity in $\mathbb{M}_{3}$.
} 
hypothesis is rejected, we see that including openness improves the datacompatibility of the efficiency equation. ${ }^{7}$

Restriction three is more specific and tests the possibility that openness has a shift effect on inefficiency but not a slope effect. Again, this is rejected. The implication - consistent with much of the endogenous growth literature - is that openness has an effect on technical change enhancing efficiency.

The final restriction examines whether openness interacts with the share of ICT capital. This hypothesis reflects the view that much of the recent improvements and divergences in TFP growth across countries and sectors (in recent decades) was driven by ICT capital usage and diffusion (e.g., Oliner and Sichel (2000), van Ark and Inklaar (2005) ) and hence by positive technological spillovers between economies and sectors. Again, the hypothesis that there is no connection is rejected.

\section{Instrumenting Openness}

One possibility is that given the heterogeneity of the industry aggregates used in the study, openness may be endogenous and potentially not independent of measured (or implied) inefficiency. The last column of Table 1 considers such a case. There we re-run $\mathbb{M}_{1}$ but instrument openness with the following regression (thus generating the case $\mathbb{M}_{1}^{+}$):

$$
\widehat{O p e n}_{i j t}=\zeta_{i}+\zeta_{j}+\zeta_{o} O p e n_{i j t-1}+\xi_{i j t}
$$

where, as before, subscripts $i=1, \ldots, N, j=1, \ldots, M$, and $t=1, \ldots, T$ denote country, industry and year index respectively. $\zeta_{i}$ and $\zeta_{j}$ show country and industry-specific effects respectively, and $\xi_{i j t}$ is the usual statistical noise.

As can be seen comparing $\mathbb{M}_{1}$ with $\mathbb{M}_{1}^{+}$, parameters are not only the same sign in each case, they are also quantitatively very similar: for example

\footnotetext{
${ }^{7}$ To see if openness might be included in the cost frontier instead of in the inefficiency equation we computed the AIC test with and without the inclusion of openness in the cost function. The corresponding values are -1.595 and -2.960 respectively. According to this criterion the model with the smallest AIC test fits better the data. Based on these findings we conclude that the restricted model (without the inclusion of openness in the cost function) is a reasonable choice to describe the production process. Next, we follow the same procedure for the ICT capital. Thus when ICT capital is included into cost function the AIC test equals -1.701. Once against the restricted model (without the inclusion of ICT capital in the frontier) is preferred.
} 
in both cases, the elasticity of output with respect to inefficiency is around -0.45 , and the interaction between openness and ICT expenditures is around -2 . One can conclude therefore that the potential endogeneity of openness was not a serious statistical problem.

\section{Additional Results}

Results from our preferred model, $\mathbb{M}_{1}$, can be further used to derive some additional metrics. First, the elasticity of inefficiency with respect to openness (in absolute terms):

$$
E O P E N_{i j t}=\left|\frac{\partial u_{i j t}}{\partial O P E N_{i j t}} \frac{O P E N_{i j t}}{u_{i j t}}\right|
$$

Second, following Kumbhakar and Lovell (2000), we can decompose TFP growth (denoted as a dot above the variable) as follows, ${ }^{8}$

$$
T \dot{F}_{i j t}=\left[1-\frac{\partial c_{i j t}}{\partial y_{i j t}}\right] \dot{y}_{i j t}-\frac{\partial c_{i j t}}{\partial T}
$$

where the first component is a Scale effect ${ }^{9}$ (henceforth $S C E$ ) while the second is a technical change effect (henceforth $T P$ ). ${ }^{10}$

\footnotetext{
${ }^{8}$ Note, allocative inefficiency has been left out of the analysis. This relates to the fact that allocative inefficiency requires the specification of a shadow cost function. However, the model we employ here (the Battesse-Coelli approach) does not permit the joint estimation of a shadow cost system (i.e., the cost function plus the $n-1$ shadow cost shares) next to an additional equation where technical inefficiency is a function of some covariates. The estimation of such a system is essentially infeasible due to the complexity of the likelihood function.

${ }^{9}$ Scale economies exist when a producer's average cost per unit falls as the scale of output increases. Scale dis-economies (i.e., negative scale economies) exist when a producer's average cost per unit increases as the scale of output increases.

${ }^{10}$ One of the advantages of the Translog cost function is that it permits both positive and negative scale effects. In this sense, the Translog function can represent a production function that is not homogeneous. Within this context, constant returns to scale (CRTS) requires the following restrictions on the parameters of the cost function (1): $\gamma_{y}=1$ and $\gamma_{y i}=\gamma_{y y}=0, i=k, l$. To test the validity of this restriction imposed on model (1) we employed test statistics based on the value of the restricted and unrestricted model. The calculated $\chi^{2}(4)$ statistic equals 67.89 which is above the respective critical value. In light of this we can conclude that the hypothesis of CRTS is rejected by the data.
} 
Finally, we compute Technical Inefficiency (TI) which compares the inefficiency under the control of the firm to (stochastic) factors beyond its control. Given the estimated cost function, we can calculate the value of the residuals $\epsilon_{i j t}=v_{i j t}+u_{i j t}$ for each observation. ${ }^{11}$ The value of technical inefficiency $e^{u_{i j t}}$ can then be computed using the standard Bayes conditional probability formula (see Jondrow, Knox Lovell, Materov, and Schmidt (1982)):

$$
\mathbb{E}\left\{\frac{u_{i j t}}{\epsilon_{i j t}}\right\}=T I_{i j t}=\left\{\frac{\phi\left(\widetilde{Z}_{i j t}\right)}{1-\Phi\left(\widetilde{Z}_{i j t}\right)}-\widetilde{Z}_{i j t}\right\} \frac{\sigma \lambda}{1+\lambda^{2}}
$$

where $\lambda^{2}=\sigma_{u}^{2} / \sigma_{v}^{2}, \sigma=\sqrt{\sigma_{u}^{2}+\sigma_{v}^{2}}, Z_{i j t}=\frac{\epsilon_{i j t} \lambda}{\sigma}, \widetilde{Z}_{i j t}=\frac{\mu_{i j t}}{\sigma \lambda}-Z_{i j t}, \mathbb{E}\left(u_{i j t}\right)=$ $\mu_{i j t}=z_{i j t} \beta^{\prime}$ and $\phi\left(\widetilde{Z}_{i j t}\right)$ and $\Phi\left(\widetilde{Z}_{i j t}\right)$ are the respective density and cumulative density function of the standard normal.

These metrics are plotted for each country and each industry in Figures 1-3. Figure 1 suggests that a cross-country sectoral average for the elasticity of efficiency with respect to openness (indicated by EOPEN) is 0.4-0.5. Some - typically large economies - have values below that (e.g., the US, Germany, Italy, Spain). By contrast, "large" open elasticities (elasticities above unity, say) are more obviously associated with small open economies: Austria, Denmark, Finland, and the Netherlands. Sweden, bucks the trend a little: although clearly regarded as a small open economy, only in industry 2 , are large efficiency gains derived from openness.

\section{[Insert Figure 1 here]}

Overall, moreover, a sectoral clustering picture emerges: industries 2, 8 and 9 derive above-average efficiency gains from openness across countries. Thus, whilst openness is robustly identified as improving efficiency, its impacts tend to be skewed towards some particular industries (textiles and equipment) and some particular countries (i.e., mostly small open economies).

\footnotetext{
${ }^{11}$ Heteroscedasticity in the symmetric error term can lead to biases in measures of the technical efficiency index: testing this term for heteroscedasticity in the baseline $\mathbb{M}_{1}$ model using the Breusch and Pagan (1979) test we obtain a value equal to 5.06 with a p-value of 0.24 . This result clearly indicates that the null of homoscedasticity cannot be rejected.
} 
The impact of ICT-related capital expenditures when interacted with openness (indicated by EOPICT) is also robustly detected across countries and sectors. Its greatest impact seems to be felt most in (typically high valued-added) industries 2 and 8-10. Interestingly Denmark emerges as an economy where ICT usage seems to have a quite strong across-the-board impact on reducing inefficiency.

Figure 2 shows a pattern of strong country performers: Sweden has the highest TFP growth of all countries in industries 3,5,7-10. Although, the differences are often not large. Sweden is simultaneously a high TFP economy with a generally low openness-efficiency elasticity, despite being a prototype small open economy; its performance appears driven more by strong TFP growth (itself buttressed by technical spillovers) and less from technological spillovers that curtail inefficiencies.

\section{[Insert Figure 2 here]}

Finally, on technical efficiency $T E$, derived as,

$$
T E_{i j t}=e^{-T I_{i j t}}
$$

we observe considerable heterogeneity between countries (see Figure 3). Many industries are on average near their full technical efficiency. The horizontal line shows the average value. However, the overall mean value is pulled down by some relatively poorly-performing industries, typically those in categories 8 and 9. Some economies, such as Canada, have relatively high and stable levels of technical efficiency across sectors, whilst others, such as Denmark, Germany, Sweden and the US, exhibit considerable variability.

Finally, Table 2 summarizes all of the metrics of the above figures in a perhaps more user friendly way. We re-scale the US values of each coefficient to unity and express those of the other countries relative to that.

[Insert Figure 3 here]

[Insert Table 2 here] 


\section{Conclusion}

For all its persuasiveness, empirically establishing a positive link between openness and growth - and thus between openness and efficiency - has proved somewhat elusive. We showed that at a sectoral level - in the context of a stochastic cost function analysis - that such effects could in fact be actively uncovered. This was robust to functional form choices - although the mis-specified Cobb-Douglas case apparently underestimates the impact of openness on efficiency.

Our results suggest both some marked heterogeneities as well as some clustering. For example, there appears to be large vs. small economy effects: smaller economies are generally far more reliant on openness to trade and technical diffusion to improve efficiency. On the other hand, there is some uniformity in the sense that some particular industries (e.g., 2, 8 and 9) across all economies derive above-average efficiency gains from openness.

Further, those who have pinpointed ICT capital usage as a driver of efficiency can find support among our results. Finally, an aspect of policy relevance may be to investigate why certain industries do not derive large efficiency gains from openness: is it related to an existing dominant position in the international market, or does it instead reflect barriers to entry.

\section{ACKNOWLEDGEMENTS}

We thank two anonymous journal referees for very helpful suggestions, editor Tim Barmby, Miguel A. León-Ledesma, Joseph Pearlman and Alpo Willman for comments and discussions as well as participants at numerous seminars and workshops. The views expressed are not necessarily those of the European Central Bank. 


\section{References}

Battese, G., and S. Broca (1997): "Functional Forms of Stochastic Production Functions and Models of Technical Inefficiency Effects: A Comparative Study for Wheat Farmers in Pakistan," Journal of Productivity Analysis, 8, 395-414.

Battese, G. E., And T. J. Coelli (1993): "A stochastic frontier production function incorporating a model for technical inefficiency effects," Working Papers in Econometrics and Applied Statistics No 69, Department of Econometrics, University of New England.

(1995): "A Model for Technical Inefficiency Effects in a Stochastic Frontier Production Function for Panel Data," Empirical Economics, 20(2), 325-32.

Breusch, T. S., and A. R. Pagan (1979): "A Simple Test for Heteroscedasticity and Random Coefficient Variation," Econometrica, 47(5), 1287-94.

Brynjolfsson, E. (1993): "Productivity Paradox of Information Technology," ACM Communications, 36, 66-77.

Chirinko, R. S. (2008): " $\sigma$ : The Long and Short of It," Journal of Macroeconomics, 30, 671-686.

Christopoulos, D. (2000): "The Demand for Energy in Greek Manufacturing," Energy Economics, 2, 569-586.

Edwards, S. (1998): "Openness, Productivity and Growth," Economic Journal, 108, 383-98.

Farsi, M., M. Filippini, and W. Greene (2005): "Efficiency Measurement in Network Industries: Application to the Swiss Railway Companies," Journal of Regulatory Economics, 28(1), 65-86.

Fuss, M. (1977): "Demand for Energy in Canadian Manufacturing," Journal of Econometrics, 5, 89-116. 
Fuss, M., D. McFadden, and Y. Mudlak (1978): "A Survey of Functional Forms," in Production Economics, Vol. 2, ed. by M. Fuss, and D. McFadden, pp. 228-249.

Greene, W. H. (2005): "Reconsidering Heterogeneity in Panel Data Estimators of the Stochastic Frontier Model," Journal of Econometrics, 126, 269-303.

Griffin, J., And P. Gregory (1976): "An Intercountry Translog Model of Energy Substitution Responses," American Economic Review, 66, 391414 .

Jondrow, J., C. A. Knox Lovell, I. S. Materov, and P. Schmidt (1982): "On the estimation of technical inefficiency in the stochastic frontier production function model," Journal of Econometrics, 19(2-3), 233238.

Jones, C. I. (2003): "Growth, Capital Shares, and a New Perspective on Production Functions," Mimeo, University of California Berkeley.

Klump, R., P. McAdam, and A. Willman (2007a): "Factor Substitution and Factor Augmenting Technical Progress in the US," Review of Economics and Statistics, 89, 183-92.

(2007b): "The Long-Term SucCESs of the Neo-Classical Growth Model," Oxford Review of Economic Policy, 23(1), 94-114.

Kmenta, J. (1967): "On Estimation of the CES Production Function," International Economic Review, 8(2), 180-189.

Kumbhakar, S., and C. K. Lovell (2000): Stochastic Frontier Analysis. Cambridge University press.

León-Ledesma, M. A., P. McAdam, and A. Willman (2010): "Identifying the Elasticity of Substitution with Biased Technical Change," American Economic Review, 100(4), 1330-1357.

MAS, M. (2006): "Infrastructures and ICT: Measurement Issues and Impact on Economic Growth," EUKLEMS Working Papers No 12. 
McAdam, P., and A. Willman (2013): "Medium Run Redux," Macroeconomic Dynamics, (forthcoming).

McQuinn, K. (2009): "The United States as a growth leader for the Euro Area - A multi-sectoral approach," Research Technical Papers 13/RT/09, Central Bank of Ireland.

Miller, M. S., and P. M. Upadhyay (2000): "The Effects of Openness, Trade Orientation, and Human Capital on Total Factor Productivity," Journal of Development Economics, 63, 399-423.

Oliner, S. D., And D. E. Sichel (2000): "The Resurgence of Growth in the Late 1990s," Journal of Economic Perspectives, 14, 3-22.

Reifschneider, D., and R. Stevenson (1991): "Systematic departures from the frontier: A framework for the analysis of Firm Inefficiency," International Economic Review, 32, 715-723.

Solow, R. (1987): "We'd better watch out," New York Times Book Review, July 12 .

VAN ARK, B., And R. InklaAR (2005): "Catching Up or Getting Stuck? Europe's Problems to Exploit ICT's Productivity Potential," EUKLEMS Working Papers No 7. 
Table 1: Estimation Results and Parameter Restrictions

\begin{tabular}{|c|c|c|c|c|c|}
\hline Parameters & $\mathbb{M}_{1}$ & $\mathbb{M}_{2}$ & $\mathbb{M}_{3}$ & $\mathbb{M}_{4}$ & $\mathbb{M}_{1}^{+}$ \\
\hline & \multicolumn{2}{|c|}{ Translog } & \multicolumn{2}{|c|}{ Cobb-Douglas } & Translog \\
\hline$\alpha$ & $-0.684^{* * *}$ & $-0.884^{* * *}$ & $0.091^{* * *}$ & $0.215^{* * *}$ & $-0.878^{* * *}$ \\
\hline$\gamma_{k}$ & $-0.065 * * *$ & $-0.053^{* * *}$ & $0.020^{* * *}$ & $0.010^{* * *}$ & $-0.076^{* * *}$ \\
\hline$\gamma_{l}$ & $0.233^{* * *}$ & $0.221^{* * *}$ & $0.109^{* * *}$ & $0.056^{* * *}$ & $0.097^{* * *}$ \\
\hline$\gamma_{k l}$ & $0.018^{* * *}$ & $0.017^{* * *}$ & - & - & $0.0218^{* * *}$ \\
\hline$\gamma_{k T}$ & -0.0002 & $-0.0002^{*}$ & - & - & -0.0004 \\
\hline$\gamma_{l T}$ & -0.00009 & $-0.007^{* *}$ & - & - & -0.0003 \\
\hline$\gamma_{k k}$ & 0.0005 & $0.002^{*}$ & - & - & 0.0002 \\
\hline$\gamma_{l l}$ & $-0.048 * * *$ & $-0.034^{* * *}$ & - & - & $-0.057 * * *$ \\
\hline$\gamma_{k y}$ & $0.003^{* *}$ & $0.003^{*}$ & - & - & $0.003^{* *}$ \\
\hline$\gamma_{l y}$ & $-0.008^{* *}$ & $-0.006^{* *}$ & - & - & $-0.006^{* *}$ \\
\hline$\gamma_{y}$ & $1.168^{* * *}$ & $1.213^{* * *}$ & $0.996^{* * *}$ & $0.989^{* * *}$ & $1.129 * * *$ \\
\hline$\gamma_{y y}$ & $-0.017^{* * *}$ & $-0.251^{* * *}$ & - & - & $-0.017^{* * *}$ \\
\hline$\gamma_{T}$ & -0.0009 & $0.002^{*}$ & $0.001^{*}$ & -0.0007 & -0.0004 \\
\hline$\gamma_{T T}$ & $-0.00006^{* *}$ & 0.0004 & - & - & $-0.00007^{* *}$ \\
\hline Austria & $-0.448^{* * *}$ & $-0.394^{* * *}$ & $-0.233^{* * *}$ & $-0.303^{* * *}$ & $-0.462^{* * *}$ \\
\hline Canada & $-0.449 * * *$ & $-0.382^{* * *}$ & $-0.214^{* * *}$ & $-0.306^{* * *}$ & $-0.466^{* * *}$ \\
\hline Spain & $-0.425^{* * *}$ & $-0.355^{* * *}$ & $-0.172^{* * *}$ & $-0.277^{* * *}$ & $-0.445^{* * *}$ \\
\hline Finland & $-0.435^{* * *}$ & $-0.382^{* * *}$ & $-0.245^{* * *}$ & $-0.308^{* * *}$ & $-0.457 * * *$ \\
\hline Italy & $-0.409 * * *$ & $-0.324^{* * *}$ & $-0.134^{* * *}$ & $-0.259^{* * *}$ & $-0.433^{* * *}$ \\
\hline Netherlands & $-0.536^{* * *}$ & $-0.405 * * *$ & $-0.096^{* * *}$ & $-0.359 * * *$ & $-0.589^{* * *}$ \\
\hline USA & $0.044^{* * *}$ & $0.160^{* * *}$ & $0.306^{* * *}$ & $0.160^{* * *}$ & $0.022^{* * *}$ \\
\hline Germany & $0.049^{* * *}$ & $0.121^{* * *}$ & $0.255^{* * *}$ & $0.202^{* * *}$ & $0.0308^{* * *}$ \\
\hline Denmark & $0.018^{* * *}$ & -0.011 & $0.009^{* * *}$ & $0.071^{* * *}$ & $0.0347^{* * *}$ \\
\hline Food & 0.005 & - & - & 0.002 & 0.005 \\
\hline Textiles & $0.002^{* * *}$ & - & - & 0.001 & $0.018^{* * *}$ \\
\hline Wood & -0.002 & - & - & -0.014 & -0.004 \\
\hline Paper & $-0.016^{* * *}$ & - & - & $-0.016^{*}$ & $-0.013^{* * *}$ \\
\hline Chemicals & $-0.010^{* *}$ & - & - & $-0.028^{* * *}$ & -0.009 \\
\hline Non Metallic MP & -0.006 & - & - & -0.007 & -0.006 \\
\hline Basic Metal & 0.004 & - & - & 0.008 & 0.003 \\
\hline Machinery & $-0.107^{* * *}$ & - & - & $-0.138^{* * *}$ & $-0.109^{* * *}$ \\
\hline \multirow[t]{2}{*}{ Transport } & -0.009 & - & - & -0.007 & -0.005 \\
\hline & \multicolumn{5}{|c|}{ Inefficiency Equation } \\
\hline $\bar{\beta}$ & $1.734^{* * *}$ & $3.032^{* * *}$ & $-0.177^{* * *}$ & $0.803^{* * *}$ & $1.915^{* * *}$ \\
\hline$\beta_{o}$ & $-0.456^{* *}$ & $-0.735^{*}$ & $-0.041^{* * *}$ & $-0.027^{* * *}$ & $-0.444^{*}$ \\
\hline$\beta_{o T}$ & $-0.090^{* * *}$ & -0.038 & 0.001 & $-0.037^{* * *}$ & $-0.135^{* *}$ \\
\hline$\beta_{\text {oict }}$ & $-2.450 * * *$ & $-5.288^{* *}$ & $-0.319^{* * *}$ & $-0.958^{* * *}$ & $-2.181^{* * *}$ \\
\hline$\beta_{T}$ & $0.228^{* * *}$ & $0.275^{* * *}$ & $0.125^{* * *}$ & $0.087^{* * *}$ & $0.259^{* * *}$ \\
\hline$\sigma=\sqrt{\sigma_{u}^{2}+\sigma_{v}^{2}}$ & $0.529^{* * *}$ & $0.640^{*}$ & $0.109^{* * *}$ & $0.358^{* * *}$ & $0.568^{* * *}$ \\
\hline$\lambda=\sigma_{u} / \sigma_{v}$ & $45.197^{* * *}$ & $24.99^{*}$ & $1.704^{* * *}$ & $14.450^{* * *}$ & $63.426^{* * *}$ \\
\hline \multirow[t]{2}{*}{ Log Lik. } & 3591.9 & 3268.4 & 2559.9 & 3183.6 & 3613.7 \\
\hline & \multicolumn{5}{|c|}{ Parameter Restrictions on $\mathbb{M}_{1}$} \\
\hline 1. $\sum_{j} \sum_{i} \gamma_{i j}=0, i \neq j \in[K, L, T]$ & $\chi_{9}^{2}=816.72^{* * *}$ & & & - & \\
\hline 2. $\beta_{o}=\beta_{o T}=\beta_{o i c t}=0$ & $\chi_{3}^{2}=646.97^{* * *}$ & & & - & \\
\hline 3. $\beta_{o T}=\beta_{\text {oict }}=0$ & $\chi_{2}^{2}=1613.75^{* * *}$ & & & - & \\
\hline 4. $\beta_{\text {oict }}=0$ & $\chi_{1}^{2}=218.84^{* * *}$ & & & - & \\
\hline
\end{tabular}

Note: ${ }^{* * *},{ }^{* *}$ and $*$ respectively indicate the $1 \%, 5 \%$, and $10 \%$ level of significance. 


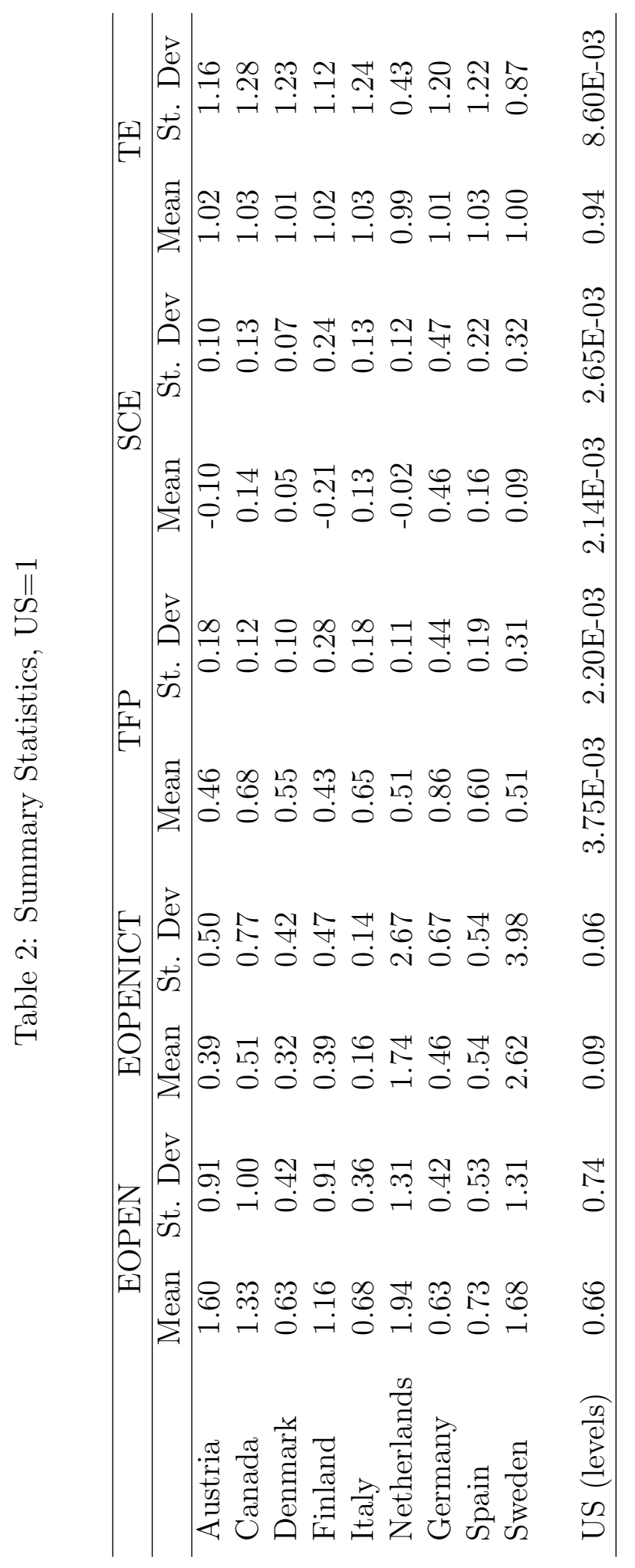


Figure 1: The Elasticity of Openness with respect to Efficiency
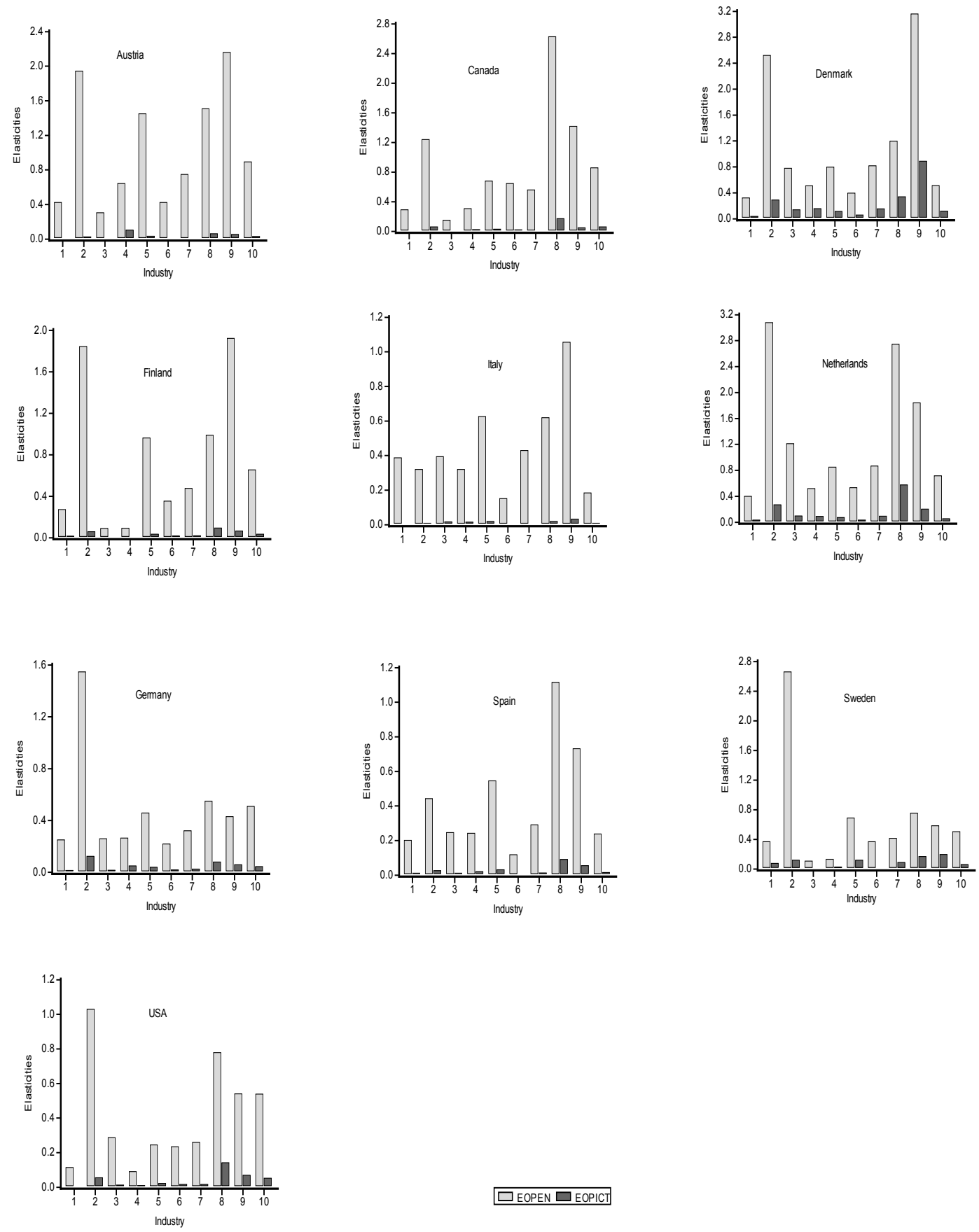

Note: These graphs plot for each industry category within a country, the elasticity of openness with respect to efficiency as determined by equation (7). The first grey column in the simple openness elasticity, the second in black is the cross elasticity of efficiency with respect to openness when interacted with ICT expenditure. 
Figure 2: Total Factor Productivities and Scale Economies
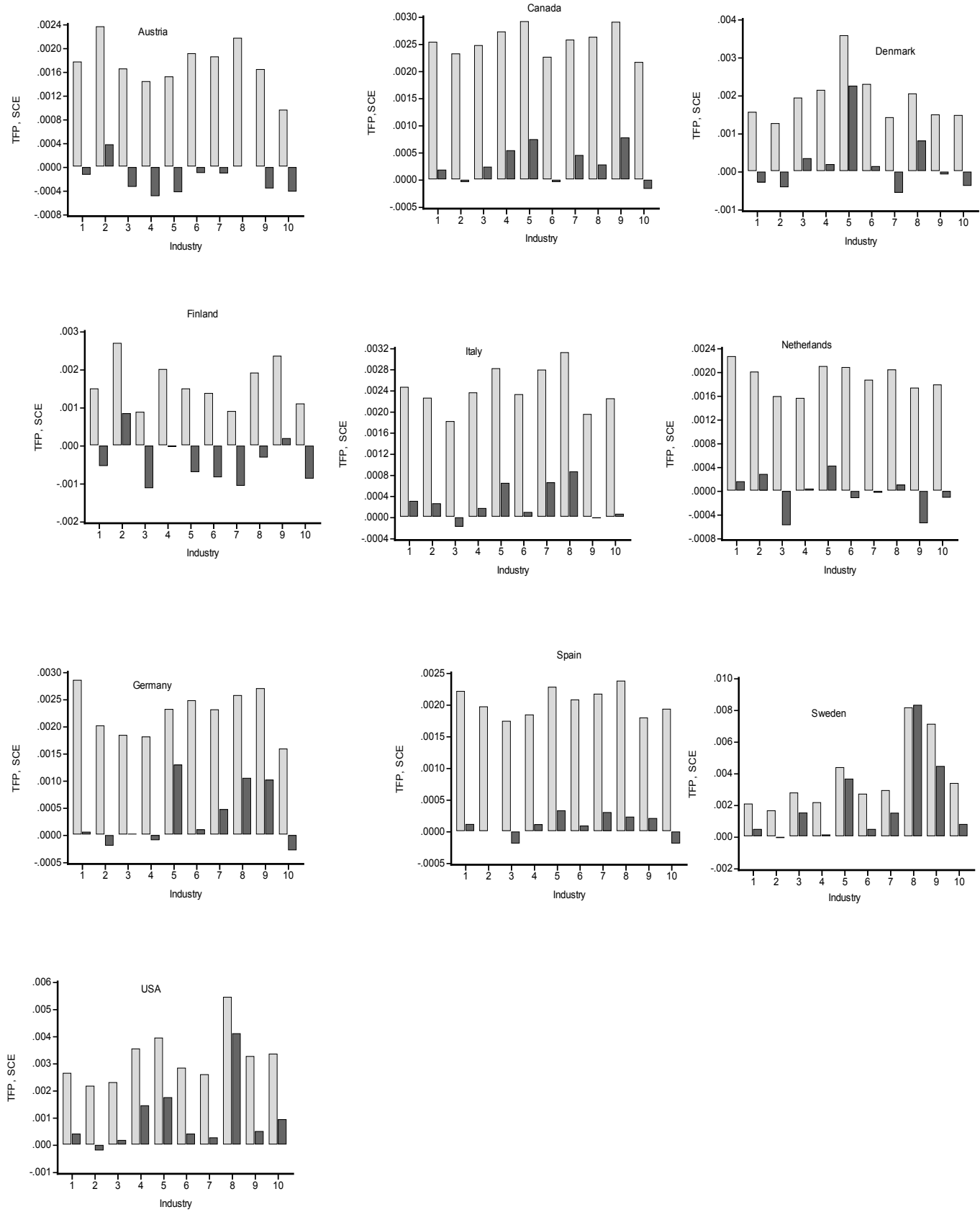

口TFP 口SCE

Note: These graphs plot for each industry category within a country, Total Factor Productivities as determined by equation (8) and Scale Economies as determined by the sub-term in (8) of $\left[1-\frac{\delta c_{i j t}}{\delta y_{i j t}}\right] \dot{y}_{i j t}$. 
Figure 3: Technical Efficiency (TE)
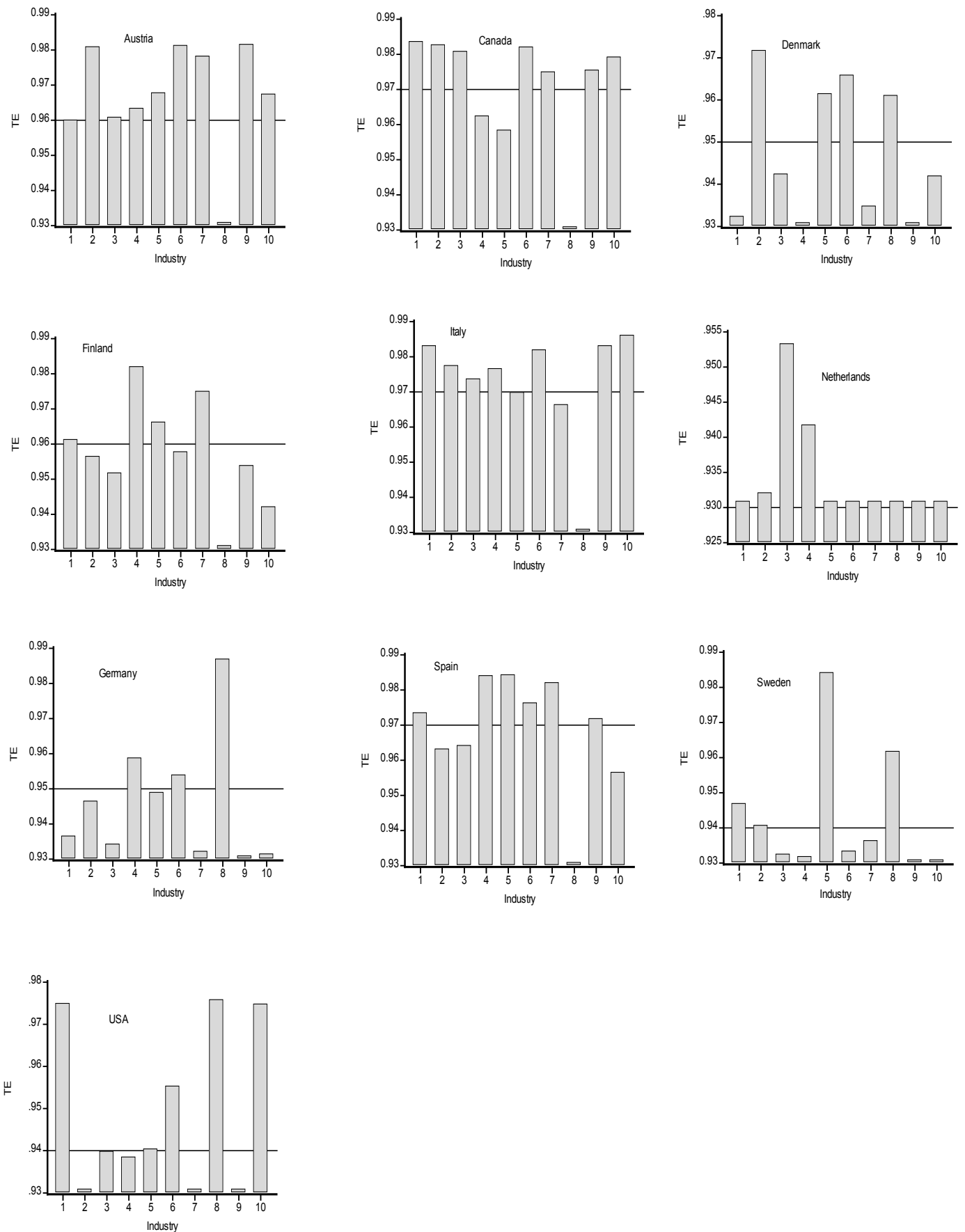

Note: These graphs plot for each industry category within a country, Technical Efficiency as determined by equations (9) and (10). 